\title{
Efficiency and Competition between Payment Instruments
}

\author{
JOSEPH FARRELL * \\ University of California, Berkeley
}

\begin{abstract}
A payment instrument that disproportionately charges merchants (as with high interchange) can take business from others that offer the two-sided customer better deals. This competitive bias arises because merchants internalize cardholders' benefits (even without merchant competition). Use of an instrument with high merchant fees also raises prices paid by other consumers, a non-pecuniary externality. While it can be allocatively efficient to tax rivals of a firm (or cooperative) with market power, competition policy urges otherwise. The competitive bias and the externality on other consumers vanish when competing payment instruments are equally costly to merchants, suggesting a simple policy benchmark.
\end{abstract}

\section{Introduction}

Card-based payment instruments such as VISA or debit networks process transactions worth trillions of dollars annually. ${ }^{1}$ The customer for these intermediation services is twosided: an often fleeting coalition of cardholder and merchant who jointly consume the payment intermediation service. Does it matter for efficiency and competition whether a payment instrument charges merchants a lot and cardholders less (possibly less than nothing) or vice versa? ${ }^{2}$ That is, does the fee pattern - as distinct from its overall level matter?

The economics literature has shown that (under price coherence) it does matter. ${ }^{3}$ But this literature has suggested that the effects on overall efficiency, and any biases when

\footnotetext{
* Mailing address. University of California, Berkeley, Department of Economics, 549 Evans Hall \#3880 Berkeley, CA 94720-3880, Phone: (510) 642-9854, E-mail: farrell@econ.berkeley.edu. I became interested in these issues through an analysis of Australian interchange fee policies. The Reserve Bank of Australia supported that analysis but not this paper. For helpful comments or discussion, I thank Severin Borenstein, Alan Frankel, Michael Katz, Patrick Rey, Jean-Charles Rochet, Marius Schwartz, Jean Tirole, John Vickers, and Julian Wright; of course they are not responsible for my views.

${ }^{1}$ See for example Evans and Schmalensee (2005a).

${ }^{2}$ Because the payment instrument's customer is two-sided, it could be confusing to refer to the two sides as the merchant and the (merchant's) "customer." Thus I call them the merchant and the "cardholder" or "consumer."

3 "Price coherence" means that the merchant charges nominally the same price for consumers using different payment instruments. It is widespread among merchants even where no law or agreement requires it. Wright (2003a) and others have noted that this would not survive under perfect competition among merchants.
} 
payment instruments choose their fee patterns, are complex and intractable. ${ }^{4}$ I take a different approach, which I believe is more consistent with competition policy. This approach stresses that competition can flourish only if the customer tends to choose the best among the offers made to it; I call this the customer choice criterion. This normally (in markets with simple customers) goes almost without saying, but because of an inherent asymmetry in team spirit between merchant and cardholder, payment instruments' fee structures often bias the choice of payment instrument by that imperfect team, the twosided customer.

The customer choice criterion is a competition standard, not a welfare standard. It aims to protect customer sovereignty and the competitive process that relies on it. In contrast, much of the modern literature seeks to assess whether a bias in customer choice might compensate for some other distortion. I argue that the latter approach risks undermining the basic competitive process. Sections 2 and 3 discuss this general point and its policy implications in relatively non-technical terms. I have tried to make these sections useful for economically educated readers who are not industrial organization theorists or paymentinstrument experts.

Starting with section 4, the paper becomes more technical. Like Schwartz and Vincent (2006), I consider a single merchant with a residual demand curve that may or may not reflect competition from other merchants. A payment instrument sets a merchant fee $m$ and a cardholder fee $f$; I call $m+f$ the fee level and its decomposition into $m$ and $f$ the fee structure. I show that, given its residual demand curve, a merchant's profits are changed surprisingly little by a small change in a payment instrument's fee pattern that leaves unchanged its fee level - that is, by equal and opposite small changes in $m$ and $f$. This is because the merchant internalizes cardholder-side fees and non-price benefits through their effect on demand. For example, if $m$ increases slightly and $f$ decreases slightly, the merchant bears an additional cost but its demand curve rises because (at a given nominal price $p$ for the merchant's goods) the full price $p+f$ offered to cardholders is lower; these effects nearly cancel. Merchant internalization was noted by Rochet and Tirole (2002), but in their analysis (for technical reasons that I discuss) it depended on competition among merchants.

Internalization colors competition among payment instruments with different fee patterns. Without internalization, one might naturally expect merchants to push for a payment instrument with low merchant fees, while cardholders push for one with low cardholder fees. But with strong internalization, the merchant will (approximately) favor instruments that are best for merchant and cardholder jointly - not for the merchant narrowly. Because cardholders do not conversely internalize merchant benefits, the twosided customer is predictably biased toward a payment instrument that appeals narrowly to cardholders, unless cardholders' selfish interests are also well aligned with the best twosided bargain. ${ }^{5}$ In general they are so aligned only if merchants' total acceptance cost (including both merchant fees and non-price costs and benefits) is equal across payment instruments. Otherwise, as long as the cardholder has any significant say (and most observers believe that cardholders are "in the driver's seat"), there is a principal-agent problem within the two-sided customer: its choice is biased towards an instrument that

\footnotetext{
${ }^{4}$ See for instance Guthrie and Wright (2006) or Evans and Schmalensee (2005b).

${ }^{5}$ Guthrie and Wright (2006) also explore the implications of this asymmetry. They also stress that, because of network effects, the incentives at this level do not necessarily govern: an instrument that is generally expected to succeed will tend to do so. See also Rochet and Tirole (2006).
} 
treats the cardholder well and the merchant (in narrow terms) badly - in the case of fourparty instruments such as VISA, towards an instrument with high interchange fees.

Nor is this just a private principal-agent problem within each two-sided customer (merchant-cardholder coalition): there are proportionally large spillovers. If one payment instrument shifts its fee structure toward higher merchant-side fees, the merchant optimally responds by raising its nominal price, harming consumers who use other payment instruments, and reducing the efficiency of their trade with the merchant. In this sense a payment instrument with high merchant fees taxes trade between customers and its rival instruments. ${ }^{6}$ This spillover is, to first order, equal to the full amount by which a naïve calculation would suggest the change in fee structure harms the merchant. To first order, then, the consequence of a fee structure change might be described as a transfer to card customers from non-card customers (as in Borenstein 1996). ${ }^{7}$ This makes card participation more attractive to consumers, and hence more apt to be chosen by two-sided customers when consumers are in the driver's seat, in a way that does not consist of true value creation by the card system or its offering a better deal to its customers overall.

\section{Efficiency and competition}

While competition policy is aligned with efficiency, it does not try to use all available tools and information to seek efficiency, as imaginative regulation might. Rather, it protects and relies on the "competitive process." This process operates through customer choice and the incentives that customer choice creates for vendors. When customers choose among the deals offered to them, products that give users a better deal get much more business than those that offer less. Normally this incites firms to offer good deals, and evolutionarily promotes growth of the best deals offered and demise or improvement of the worse ones. This in turn tends to promote efficiency in at least two ways: prices evolve toward costs, and more-efficient firms (who are better able or more willing to offer good deals) out-grow their less-efficient rivals.

In ordinary one-sided markets, we usually expect without much discussion that each customer tends to choose well among the deals he is offered, so attention focuses on other factors affecting firms' choices of what to offer. At that level firms may seek to thwart the competitive process by discouraging one another from offering customers better deals, or by trying to weaken one another so as to make better deals infeasible. But the competitive process can also break down, arguably even more fundamentally, if customers systematically fail to choose well among the choices on offer.

Competition needn't break down badly just because customers fail to be full-blown economic optimizers. But if customer choice is unresponsive to better offers then better offers won't be made, and if made won't particularly thrive. And if customer choice is

\footnotetext{
${ }^{6}$ As we will see, the "tax" metaphor is imperfect: the merchant often makes less profit from non-card customers as a result, and the card system and cardholders of course do not collect money directly from noncard customers. Thus it is a "tax" in the sense of a discouragement, not in the sense of a revenue source, except indirectly in that by discouraging non-card trade, the card system can extract more profit.

${ }^{7}$ Like the "tax" metaphor, the "transfer" metaphor is imperfect; the reason is much the same. Since the merchant may well collect less profit from non-card customers, and there is no direct payment from them to card customers, the mechanics of a "transfer" are problematic or at least puzzling. However, the non-card customers lose roughly as much as the card customers gain, while the merchant's overall profit barely changes, so it is at least "like" a transfer.
} 
significantly biased, then the market outcome will reflect those biases. Thus reasonably good customer choice among the available options is a key part of the competitive process, and protecting it can be a necessary concern of competition policy. While in simple markets this is often so automatic as to need little attention, in two-sided markets it is not immediately clear what it means, whether it is automatic, or how to protect and promote it if need be. These are the questions that I seek to address below.

The seminal article by Rochet and Tirole (2002) is technical as well as path-breaking. Perhaps because of its technical challenges, some policy or political economy assumptions implicit in it, and in literature that follows it, have been little remarked. In this section I explain how those implicit assumptions strike at the foundation of the competitive process as I understand it. I say this with great respect for Professors Rochet and Tirole and their work. They uncovered the fundamental merchant internalization in payment instruments, and their analysis illuminated efficiency implications of interchange and no-surcharge rules, undoubtedly a good thing to examine. Nevertheless, I want to ensure that economists and policymakers recognize that a competition policy perspective may be quite different in this case. Because we normally expect that competition policy is well aligned with efficiency, this divergence deserves much more discussion, which I hope this paper will provoke. ${ }^{8}$

Consider two competing payment services, CARD and CASH. Because of market power, CARD is priced at above its marginal cost, while CASH is priced at its marginal cost. Allocative efficiency is at risk in that, because of CARD's markup, some business goes to CASH that would more efficiently go to CARD.?

That inefficiency could be averted by lowering the CARD price toward its marginal cost, or alternatively by raising the CASH price. Rochet and Tirole showed how, under price coherence (whether voluntary or enforced by statute or by a "no surcharge" contract), changing the fee structure of CARD so as to load more onto merchants and less onto cardholders does a mixture of these things - in a sense. It does not do so from the point of view of the two-sided customer: if the cardholder and merchant could jointly optimize their choice given all the fees, a change in CARD fee structure would have no effect. The shift instead just encourages cardholders to use CARD rather than CASH, partly by lowering the full price to cardholders of buying the good using CARD, and partly by raising the full price of doing so using CASH. The shift meanwhile makes merchants hope that consumers will use CASH, but (for reasons that Rochet and Tirole were the first to explore) merchants do not immediately cease to accept CARD payments.

Rochet and Tirole observe that (a) if judiciously applied, this mechanism can restore the efficient quantity allocation that would otherwise be spoiled by CARD's (in their model, specifically CARD issuers') exercise of market power, but (b) if controlled by CARD issuers, it may well be taken too far. A subsequent literature continues in the spirit that (a) would be good but (b) might be bad, as might the possibility (c) that the

\footnotetext{
${ }^{8}$ For instance, one might ask whether pro-competition policy is likely to be more robust or to require less information in general than a strategy of promoting allocative efficiency at all levels; I thank Patrick Rey for this suggestion.

${ }^{9}$ Another risk to allocative efficiency is that some customers might buy nothing, rather than buy using the overpriced CARD, even though their value for a transaction using CARD exceeds its marginal cost: this arises in Schwartz and Vincent (2006) and in this paper. Rochet and Tirole (2002) assume that this problem does not arise: in their model, each customer wants just one transaction and values it enough so that (in the relevant range) prices never completely deter demand: they only steer it between CARD and CASH, so only the relative prices of CARD and CASH affect allocative efficiency.
} 
mechanism is not used enough. I argue, on the contrary, that even (a) is troublingly inconsistent with the competitive process.

\subsection{Broad concerns and the customer choice criterion}

While the mechanism by which a change in fee structure (or interchange) does these things involves analysis specific to two-sided markets and perhaps even to payment instruments, some competitive concerns about these results and their interpretation are much broader.

\subsubsection{Bias in (two-sided) customer choice}

I've discussed this in general terms above. Even case (a) above, where the bias (shifting two-sided customer choice away from what is best for the customer among available offers) "only" restores allocatively efficient choices, it still threatens the competitive process in my view. I hope this logic is already clear; if not, perhaps the following paragraph can help.

\subsubsection{Ex post inefficient demand penalties are central to competition}

A firm that sets its price level above marginal cost typically loses some sales, relative to marginal-cost pricing. Ex post, this loss of demand is typically inefficient, so techniques to reverse it seem to enhance efficiency - and, ex post, they do. But of course if a firm can exploit such techniques, it evades the ex ante price discipline otherwise imposed by its demand curve. In this sense, techniques to shift customer choice away from what is best for customers given the offers made to them, threaten the basic market discipline of the competitive process: a firm that makes a better offer makes more sales. Weakening that discipline can let firms extract excess profits and/or let inefficient providers thrive. The former may be less of a concern than the latter in the case of four-party payment instruments if intra-system competition is nearly perfect: then, the problem is not so much excess profits or inefficient selection among issuers or acquirers, but the possibility that the payment instrument as a whole thrives even where it is inefficient or does not offer the best deal. ${ }^{10}$

The above thinking suggests the following:

Customer Choice Criterion. To support efficient competition, policy should seek to support - and should stop sellers from undermining - customers' ability to choose the best deal offered to them. In particular, it is good, not bad, in this respect if customers' choices reflect prices, even though prices are not themselves part of marginal resource costs. Thus this criterion need not coincide with allocatively efficient choice by customers among a given set of offers (although it may well serve efficiency in the longer run).

This criterion connects competition policy with consumer protection and with concerns about corruption. Corruption features biased choices by imperfectly jointly optimizing two-sided customers (politicians and taxpayers, or executives and shareholders); it has this in common with my analysis of payment instrument fee structure. Of course interchange and corruption are very different in many ways, and I don't seek to "equate" them,

\footnotetext{
${ }^{10}$ I stress "where it is inefficient," not "if it is [generally] inefficient." In particular, it may very well be that credit card use is very efficient in some transactions; the concern would be that, because of the pricing structure, consumers also use credit where it is inefficient (for the two-sided customer and perhaps socially). This is a convenient point to note (with thanks to Julian Wright for pointing it out) that whereas the model sketched below talks of customers using various payment instruments, choice by each customer across transactions may be a better description; I do not think it would make any great difference to the analysis. Finally, note that full dissipation of profits is not the same as near-perfect competition.
} 
especially morally. But they share the feature that competition may go wrong when vendors give the "driver's seat" member of the two-sided customer very different choice incentives than its partner.

\subsection{Concerns more specific to payment instruments}

\subsubsection{Externality on non-participants}

As noted above, a change in the fee structure of one payment instrument directly affects the total price paid by its cardholders; it also affects the nominal price set by the merchant and hence the total price paid by consumers who use other instruments. In particular, if one payment instrument shifts toward charging more to merchants and less to cardholders, that raises the merchant's expected marginal cost of sales, and hence (under price coherence) raises the price to consumers using other instruments. Unlike the internal vertical externalities that might be ameliorated by changes in fee structure, this is an effect on nonparticipants.

Calculation 2 below, ${ }^{11}$ generalizing Borenstein (1996), shows that to first order this negative externality is equal to the gain to cardholders from their lower fees and hence somewhat lower total price; Schwartz and Vincent (2006), in a finer calculation of the balance, show that either effect may dominate and that the net efficiency effects are ambiguous ex post. But even if the cardholder gain exceeds the loss to non-card customers, there is surely reason for concern if a firm or joint venture can extract surplus from noncustomers and provide it to its customers, or if it solves its internal incentive problems in a way that commensurately hurts outsiders. ${ }^{12}$

\subsubsection{Taxing rivals' trade}

Calculation 1 below also lets us sharpen this concern about the externality on non-card consumers, and put it into more conventional competition-policy terms. The Calculation states that the merchant's profits are unaffected to first order (in practical terms, this means that when payment system fee levels and changes in their structures are small relative to the merchant's markups, the great bulk of the effect is on consumers). Thus the shift lowers the joint surplus achieved by the merchant and those consumers. In this way CARD's seemingly internal choice of fee structure can in effect raise rivals' costs, or more precisely lower the joint surplus achieved by trade using payment-instrument rivals.

Another way to express this is that the negative externality on non-card customers, although mediated through an effect on the merchant's price, is not a pecuniary externality. A pecuniary externality is also an effect on prices paid by others, but its defining feature is that there is a positive externality on sellers that balances the negative externality on buyers: the classic example is an increase in demand in a competitive market.

\footnotetext{
${ }^{11}$ Previous drafts called Calculations 1 and 2 "theorems." I have renamed them because the proofs given are somewhat heuristic. They can easily be restored to theorems for the case of linear demand, and I explain why I am confident that they are more general (as close approximations), but at this point I refrain from the term "theorem."

${ }^{12}$ A solution to an internal problem may often incidentally somewhat hurt outsiders, but here (as explored below) the outside effect is by no means a footnote to the inside effect.
} 


\subsection{The balancing role}

Fee structure also plays a genuine internal efficiency role: it helps "balance" merchant and cardholder demand (Baxter 1983, Schmalensee 2002, etc.). That role of course emerges more clearly if we zero out the problematic role. Thus suppose that there is no issuer market power in the Rochet and Tirole model. ${ }^{13}$ The model still urges nonzero interchange in general, because (for instance) if CARD payments are far more convenient for merchants than CASH payments, but consumers would just as soon pay with CASH, then a merchant-heavy fee structure helps internalize this vertical externality between CARDusing consumers and CARD-accepting merchants.

However, this internal efficiency effect is incorporated in the customer choice criterion that fee structures should not distort the two-sided customer's choice among available offers: the criterion encourages the choice of a fee structure that internalizes vertical externalities of payment-instrument choice within the two-sided customer - that is, between cardholder and merchant. But it denies that customer choice should be biased (away from what is best for the two-sided customer) so as to undo the demand penalty that a card system or its participants suffer for exercising market power. Equivalently, when CARD is priced above its marginal cost, the customer choice criterion ignores the vertical externality on CARD providers: an additional transaction increases their profits. From the point of view of ex post efficiency this may seem a little arbitrary: why do vertical externalities within (two-sided) "customers" count but those on the providers of payment instruments not? I think this is a deep question, but it is surely consistent with ordinary competition policy.

\section{$3 \quad$ Policy implications}

\subsection{Implications for fee structure}

Because Calculation 1 suggests that merchants' acceptance decisions will be inelastic to changes in fee structure (as distinct from changes in total fee level), and because (perhaps as a result) most observers see cardholders as being "in the driver's seat," it is cardholders' choice incentives that matter most in analyzing the consequences of fee structure variation.

Aligning cardholder incentives for choice of payment instrument with the (joint) interests of the two-sided customer means making the merchant indifferent. ${ }^{14}$ That is, it requires that the merchant's total acceptance costs, including merchant-side processing costs and merchant discounts as well as less-tangible convenience and security benefits, should be equal across payment instruments. This suggests a simple policy benchmark, which seeks to implement the Customer Choice Criterion for the case of payment instruments:

\footnotetext{
${ }^{13}$ In this case, the fee structure or interchange prescribed as efficient by Rochet and Tirole does not incorporate the considerations I call problematic. But a payment instrument might still use the problematic demand-shifting properties of interchange or fee structure; it just wouldn't be deemed efficient in that analysis. With constant costs, lack of market power makes participants indifferent about fee structure, but that seems an artifact of constant costs.

${ }^{14}$ If, for instance, the merchant systematically hopes that the cardholder will use CASH rather than CARD, then the cardholder's selfish choice will systematically use CARD too often relative to the joint optimum. See for instance Groves and Ledyard (1977).
} 
Merchant Indifference Criterion: The customer choice criterion holds when the merchant is indifferent among the consumer's choices of payment instrument.

Of course, non-fee transaction costs will vary across merchants and even for a given merchant across transactions, so this criterion must be interpreted as a statement about averages. Also, if it cannot hold simultaneously for all pairs of payment instruments, it is most important that it roughly hold for those pairs that are close substitutes for cardholders.

Recall that this criterion seeks to facilitate (privately) optimal choice by two-sided customers for payment instruments, from among the offers available to them. Unless marginal profits happen to be equal, it does not coincide with allocatively efficient choice among those offers, the focus of most of the recent literature. Nor does it involve regulation of overall fee levels, as a broad regulatory intervention might. In that sense, while it could be described as a (two-sided) customer welfare standard given the offers (including fee levels) made by competing payment instruments, it is not a thoroughgoing customer welfare standard, which presumably would control those fee levels. Rather, it seeks to clean and oil the gears of competition among payment instruments that set their own fee levels; that is necessary because the principal-agent problem within the two-sided customer otherwise puts sand in those gears.

\subsection{Implications for interchange}

Not all payment instruments even have interchange and as Katz (2005) stresses, interchange alone does not determine cardholder and merchant prices. Thus rather than focus on interchange I prefer to focus on the fee pattern. Nevertheless, interchange affects fee patterns and is a major locus for policy intervention.

The discussion above, and the merchant indifference criterion, implicate relative charges to merchants, not the absolute level of such charges by any one instrument. Indeed, if all instruments (including cash, though it's not easy to imagine how that would work) simultaneously increased merchant fees and reduced consumer fees by the same amount, merchant pricing would adjust in such a way that the change had no real effect.

However, given other instruments' merchant fees $m_{j}$, and provided that instrument $i$ 's interchange is passed through (not necessarily dollar for dollar) on the acquiring side so that interchange "moves" the payment instrument's merchant fees, the merchant indifference criterion yields a prescription for instrument $i$ 's interchange. As above, this must be interpreted in a broad or average sense when comparisons against instrument $j$ 's and instrument $k$ 's merchant fees would yield different answers, or when merchants differ in the non-price values they attach to the use of different payment instruments.

\subsubsection{Cost-based interchange?}

Non-fee merchant costs and benefits differ among payment instruments, and the merchant indifference criterion takes that into account. Thus fee or interchange policy aimed at the merchant indifference criterion should depend on merchant data and not only on bank or financial institution cost data.

A simple case arises if merchants view different card-based instruments as equivalent but for pricing; certainly they are similar in many ways relative to say cash or checks. Then, as far as choice between those instruments is concerned, the merchant indifference criterion urges equal merchant fees. That means that $t+c_{A}+\pi_{A}$ should be equal across the 
instruments, where $t$ is interchange (paid by acquirers to issuers, as is conventional), $c_{A}$ is the marginal resource cost of acquiring, and $\pi_{A}$ is the marginal markup of acquirers. If, as is often assumed, acquiring is highly price-competitive (or has equal absolute markups in the two instruments), this condition holds when $t=k-c_{A}$ for some constant $k$ that is equal for the two instruments. With $k=0$ this holds when interchange is "negative" and equal to acquirer marginal costs. If total system marginal costs are equal (say, to $C$ ) for both systems then we can alternatively set $k=C$ and get $t=C-c_{A}$, which is closer to what is usually meant by "cost-based interchange." But generally the merchant indifference criterion does not support cost-based interchange in principle; rather, it offers a benchmark by which to assess whether it might be pragmatically better than a status quo.

\subsection{Laissez-faire?}

Of the many externalities and inefficiencies in the economy, why seek to fix this one in particular?

One answer is that techniques to bias customer choice (here, two-sided customer choice) may be especially threatening to efficient competition. A related answer is that allowing payment instruments with market power to tax their rivals may be especially worrying, perhaps notably if interchange is collectively chosen by firms that are in other respects rivals. Third, although the distortions are small compared to the volume of retail trade affected, those volumes are immense.

Is a fee pattern loaded primarily on the inelastic (to variations in interchange!) side, i.e. merchants, just another competitive strategy? Should we just expect everyone to do it, perhaps expect those who have lowest overall net costs to be most capable of doing it successfully, and it's just part of the sometimes surprising way that competition works?

I see two important arguments against that "competition is rough-and-tumble" position. First, payment instruments differ a lot in their institutional ability to do this, and it hasn't much to do with their efficiency. Cash really can't play this game (and perhaps multi-party bilateral negotiations can't very well); and unitary instruments such as Amex or Discover may be able to do it more smoothly than four-party systems such as Visa and MasterCard, depending perhaps on internal rules or politics. Second, there are externalities on nonparticipants ("cash customers") when different payment instruments compete on this dimension, so that such a contest may be a dysfunctional form of competition. ${ }^{15}$

While this is in part a matter of judgment, it seems to me that if a payment instrument with a large market share avoids the demand penalty of relatively high overall fees by loading its fees heavily on the merchant side, making usage attractive to consumers in a way that it may well not be to the two-sided customer, and inflicting real negative externalities on non-participating consumers and on rival payment instruments, then policy intervention to make it more likely that the two-sided customer generally chooses the best available offer (as is usually automatic in a one-sided market) is well worth exploring. Although the Merchant Indifference Criterion potentially involves regulating merchant fees, it leaves the overall fee level up to the payment instruments and in that sense is competition policy rather than rate regulation.

\footnotetext{
${ }^{15}$ Macfarlane (2005) argues (a) that competition among instruments seems to increase interchange fees, and
} (b) that this is perverse. Weiner and Wright (2005) further discuss (a). 


\section{$4 \quad$ Fee structures and demand for payment instruments}

The cardholder-side transaction fee $f$ and the merchant-side transaction fee $m$ both affect demand for the payment instrument, and some early work reflected a natural guess that they might do so in a broadly separable way. Specifically, if the cardholder's benefit from transacting using the card (relative to an alternative payment instrument, say cash) is $b_{C}$ and the merchant's is $b_{M}$, then the transaction will take place using the card if and only if both $b_{C} \geq f$ and $b_{M} \geq m \cdot{ }^{16}$ Using inverse distribution functions $F$ and $G$ for cardholder and merchant non-price net benefits, one might expect a reasonable simple model to be that the number of card transactions is given, as in Schmalensee (2002, equation 1), by:

$$
Q=F(f) G(m)
$$

Working from variants of (1), Schmalensee argues that private incentives broadly mirror efficiency in that the fees to each "side of the market" should (inversely) reflect demand elasticity, and that any biases are apt to be delicate.

Natural though (1) appears, it omits merchant internalization. Internalization first appeared in the Hotelling model of Rochet and Tirole (2002); Calculation 1 below suggests that it is a robust phenomenon. This Calculation concerns the effect on a merchant's profit of a change in the fee structure of a payment instrument, i.e. a shift between cardholder charges $f$ and merchant charges $m$, holding fixed the total of those charges. It shows that such a shift has little effect on the profits made by a merchant who accepts that payment instrument, relative to the naïve calculation that the merchant "pays" the change in $m$. If such shifts had no effect (rather than very little effect) on the merchant's profit, that profit - and hence the merchant's willingness to accept this payment instrument - would take the form $H(f+m)$, using a presumably different inverse distribution function $H$ for merchant benefits. This yields:

$$
Q=F(f) H(f+m)
$$

Following Schwartz and Vincent (2006), I take as given the merchant's residual demand curve, made up as follows. I take as exogenous that a fraction $\alpha_{i}$ of consumers use payment instrument $i$, and assume that users of each payment instrument $i$ have the same demands $D$ as a function of the net price $p+f_{i}$ that they face. That is, if the merchant sets a nominal price $p$ and payment instrument $i$ imposes a cardholder fee $f_{i}$, then sales using that payment instrument will take the form $\alpha_{i} D\left(p+f_{i}\right)$ (with no subscript on $D$ ). ${ }^{17}$ (I later use this formulation to discuss the determination of these $\alpha_{i}$.)

Calculation 1. Given a payment instrument's total charges $(f+m)$, a change $\mathrm{d} m$ in $m$ accompanied by an equal and opposite change $\mathrm{d} f=-\mathrm{d} m$ in $f$ has an effect on a merchant's profits that is bounded by terms on the order of $[(f+m) / p] Q \mathrm{~d} m$, where $Q$ is the quantity sold using that payment instrument. When $(f+m) / p$ is small (as it usually is in practice), the profit impact is small compared to the naïve calculation $Q \mathrm{~d} m$.

\footnotetext{
${ }^{16}$ See for instance Rochet (2003). Institutionally, merchants do not decide on a transaction-specific basis, but the fundamental idea is nevertheless worth exploring.

${ }^{17}$ This formulation assumes that transaction charges do not vary with the transaction price, that is, are not ad valorem. I believe that the basic idea will go through with ad valorem charges.
} 
Sketch of Proof. For definiteness consider a change with $\mathrm{d} f<0<\mathrm{d} m$. While the merchant's costs increase by $Q \mathrm{~d} m$, his revenues also rise because demand from cardholders rises, since they face a total price $p+f$ that is lower by $|\mathrm{d} f|$. This implies that the net profit impact of the changes is proportional to the slope of the merchant's profit function, at a full price that depends on the payment instrument. While (assuming price coherence) that slope is generally not zero, it will be small in magnitude given that payment-instrument charges differ little across instruments relative to the retail price. The details of the proof are in the Appendix.

Thus, to first order, the merchant's incentive to accept a payment instrument relates not to its $m$ but to its $f+m$. "Merchant resistance" depends on total fees, not on merchant fees. Price coherence simply constrains the merchant to choose net prices that differ slightly among customer groups; since the profit function (as a function of price) is flat near the optimum, this has only second-order (negative) effects on profits. However, if for instance $-f=m>0$ is large then the merchant does indeed lose profits: see Schwartz and Vincent (2006).

Comment 1. If a payment instrument changes its fee structure, the change presumably applies to this merchant's rivals (if they accept this instrument) as well as to this merchant. One might well ask, therefore, whether it is legitimate to take this merchant's residual demand curve as fixed, as Calculation 1 does. Calculation 2 quantifies to first order the changes in rival merchants' net prices, and I will use that result to argue below that it is a sensible central case to assume that each merchant's residual demand curve behaves as in Calculation 1.

Comment 2. The special case of two payment instruments and a shift from $f=0=m$ for both instruments to $f=-m<0$ for one (holding the other fixed) is equivalent to the impact of a mandated discount for one class of consumers. In a different context (antitrust coupon settlements) for such a mandated discount, Borenstein (1996) showed that the merchant bears very little cost in equilibrium and that the first-order impact is a transfer to favored buyers from other buyers. Calculation 1 generalizes the first of those findings; the second is revisited in Calculation 2 below.

Comment 3. Rochet and Tirole (2002) and Wright (2003b, 2004) find that merchant resistance to $m$ is "weakened" by cardholder-side net benefits to the extent that cardholders are willing to shift between merchants in response to merchants' card acceptance. They show that merchant resistance is based not on $m$ but on $m+\alpha f$, where $\alpha$ measures how many cardholders are "informed" about merchants' card acceptance and might thus switch from one merchant to another based on acceptance (for instance, Wright attributes this to "the business-stealing effect"). I instead treat both competitive and other elasticity as part of the merchant's residual demand curve, finding that internalization of cardholder-side benefits does not depend on competition among merchants, since Calculation 1 takes the same form whether the demand is a monopoly demand or a residual demand of a merchant in a competitive business. ${ }^{18}$

\footnotetext{
${ }^{18}$ Because a firm's profit function is flatter near the peak the less elastic the firm's residual demand, the statement in the text is correct if $\mathrm{df}$ and $\mathrm{dm}$ are infinitesimal, or a smaller order of magnitude than the firm's margin, but quantitatively the demand elasticity will affect how big an effect a small but finite shift has on profits.
} 
Technically, the reason why Rochet and Tirole and work following them has treated internalization as a competitive or "strategic" effect is that, in order to solve the model explicitly, they used a Hotelling model with inelastic or L-shaped demand for goods on the part of each consumer, in which a demand boost from lower $f$ benefits a merchant only to the extent that cardholders switch merchants. The fact that cardholders who are coming to the store anyway may buy more, or that some cardholders may be at their reservation price, is omitted.

Comment 4. I find it more helpful to think of merchant resistance as based on total charges than to think of resistance as based on $m$ but "weakened" by internalization of cardholder-side benefits that decrease in $f$. For instance, Wright (2004, equation 14) gives the merchant acceptance condition in his model as

$$
b_{S} \geq m-\alpha\left[\beta_{B}(f)-f\right]
$$

where $b_{S}$ is the merchant's transactional benefit and $\beta_{B}(f)$ is the average cardholder transactional benefit conditional on the cardholder choosing to use the card when the fee is $f .{ }^{19}$ His condition could equivalently and perhaps more helpfully be written as

$$
b_{S}+\alpha \beta_{B}(f) \geq m+\alpha f
$$

better displaying that the merchant's choice depends on a weighted sum of merchant and cardholder transactional benefits net of their respective fees. ${ }^{20}$ Calculation 1 both brings out that reformulation, and suggests $\alpha \approx 1$.

Comment 5. Merchants often object to high interchange fees, whereas one might naturally think of interchange as primarily affecting fee structure, not fee level. Changes in the level of interchange will affect only fee structure if pass-through of those changes is symmetric on the acquiring and issuing sides. ${ }^{21}$ Calculation 1 also illuminates the impact on a merchant's profit of any changes in $(f, m)$, because if (for instance) $\mathrm{d} m+\mathrm{d} f>0$ (for example, interchange fees rise and the change is passed through more strongly on the acquiring side than on the issuing side), we can decompose the changes $(\mathrm{d} m, \mathrm{~d} f)$ into a pair of equal and opposite changes $(-\mathrm{d} f, \mathrm{~d} f)$ such as Calculation 1 contemplates, plus a simple increase of $\mathrm{d} m+\mathrm{d} f$ in the merchant fee (which, by the envelope theorem, affects the merchant just as one would naïvely expect). But it is also worth stressing that, for finite rather than infinitesimal changes, and starting with nontrivial levels, Calculation 1 should

\footnotetext{
${ }^{19}$ To be clear, merchant demand therefore depends on $f$ net of cardholders' non-pecuniary benefits of card use.

${ }^{20}$ Assuming that the merchant does not observe the cardholder's transactional benefit when making its acceptance choice (or perhaps ever), the expectation term is inevitable. Rochet (2003) stresses the timing and information structure of the merchant's and cardholder's choices.

${ }^{21}$ The economics of pass-through under imperfect competition are complex and subtle. With perfect competition and constant marginal costs, an increase in all competitors' marginal costs (as, for instance, an increase in interchange paid by acquirers) is $100 \%$ passed through. Some are tempted to infer that with imperfect competition pass-through will be less than $100 \%$. That is wrong. Imperfect competition and monopoly certainly open up the possibility of less than $100 \%$ pass-through, but they also open up the possibility of more than $100 \%$ pass-through, including in quite simple robust models. For instance, a monopoly facing a linear demand curve will pass through half of an increase in its marginal cost, but a monopoly facing a constant-elasticity demand curve (with elasticity above 1, of course) will pass through more than $100 \%$, as will firms who follow a proportional-markup rule of thumb. I don't know of any reason to assume that oligopoly pass-through tends to be less than $100 \%$. For recent discussion of that issue in the payment cards context see Chang, Evans and Garcia Swartz (2005) and Farrell (2005).
} 
be interpreted as showing that the main effect is not on the merchant, not that there is literally no effect on merchants.

\section{$5 \quad$ Effects on retail prices paid by non-participants}

In the Appendix, I prove: ${ }^{22}$

Calculation 2. In response to a small increase $\mathrm{d} m_{i}$ in instrument $i$ 's merchant fee $m_{i}$, combined with an equal decrease in its cardholder fee $f_{i}$, the merchant's nominal price $p^{*}$ increases by approximately $\mathrm{d} p^{*}=\alpha_{i} \mathrm{~d} m_{i} / A$, where $A \equiv \sum_{j} \alpha_{j}$. To first order, this has zero short-run effect on total consumer surplus, but transfers surplus from consumers who do not use that payment instrument to those who do.

Combining that with Calculation 1, the effect of such a matched equal-and-opposite change in fee structure is nearly ex post welfare neutral; it involves (to first order) no effect on the merchant, and the effect on consumers is redistributive; Schwartz and Vincent (2006) show that the (relatively small) net effect on total surplus is ambiguous. However, this seems a short-run focus: surely it is worrying to have a situation where a group of consumers, or an entrepreneur who signs them up, can simply extract surplus from other consumers, even if the bucket is slightly the reverse of leaky. If that concern seems too abstract, one can concretely observe that consumers or the payment instrument provider(s) may consume resources in order to join, or control, the favored rather than the disfavored group. There are few pure transfers, so that when a model predicts that an economic effect is "just a transfer" one is well advised to think again.

I think there is a good argument that the negative externality on non-card consumers is more of a concern than the vertical externality between cardholder and merchant that the fee structure's "balancing role" resolves. Essentially this would be the view that participants in a complex venture should seek ways to solve their internal problems without hurting outsiders.

Calculation 2 is stated in terms of a change in fee structure for a payment instrument. Although formally not within this model, one can also use it to discuss the effect when a payment instrument with high merchant fees grows (is used more). Specifically, if some customers shift from payment instrument $i$ to instrument $j$, that change in the $\alpha$ s appears to shift the merchant's average transaction cost, and hence $p^{*}$, in much the same way as an increase in one of the $m$.

If the total merchant acceptance cost for all payment instruments is equal, then the existence and growth of any instrument does not raise retail prices to customers using any other instrument. (And the existence and growth of a payment instrument with belowaverage merchant acceptance costs, in the right sense, lowers retail prices to customers using other instruments.)

Because this existence-and-growth externality vanishes at the same point (equal merchant acceptance costs) as the competitive bias identified above, I conjecture that they are closely related at some deep level.

This result also lets us (roughly) close the loop on Calculation 1. Recall that a question raised there (thanks to John Vickers) was whether it is legitimate to take a merchant's

\footnotetext{
${ }^{22}$ This generalizes results of Borenstein (1996) and of Schwartz and Vincent (2006).
} 
residual demand curve as fixed when payment instrument $i$ changes its fee structure. Consider (say) merchant 1's residual demand curve, and suppose for definiteness that the initiating change is $\mathrm{d} m_{i}>0$. Merchant 2 is of course also subject to the change in fee structure. Any shifts in merchant 1's residual demand curve are determined by changes in merchant 2's full or net prices $p_{2}{ }^{*}+f_{j}$. Calculation 2 says that merchant 2 increases its nominal price by $\mathrm{d} p_{2}{ }^{*}=\alpha_{i} \mathrm{~d} m_{i} / A$. Thus $p_{2}{ }^{*}+f_{i}$, its net price using instrument $i$, falls by $\left[A-\alpha_{i}\right] d m_{i} / A$, where $A$ and $\alpha_{i}$ are customer proportions for merchant 2, and $p_{2}{ }^{*}+f_{j}$, its net price using another instrument $j$, rises by $\mathrm{d} p_{2}{ }^{*}=\alpha_{i} \mathrm{~d} m_{i} / A$. There are thus two opposing shifts in merchant 1 's residual demand curve. Because customers can pay a lower net price than before at merchant 2 if they use instrument $i$, merchant 1 's residual demand falls; because they must pay a higher price than before at merchant 2 if they use any other instrument, merchant 1 's residual demand rises. ${ }^{23}$

If the number of merchant 1's customers who are on the margin of defecting to merchant 2 and using instrument $i$, relative to the number of its customers who are on the margin of defecting to merchant 2 and using other instruments, is similar to merchant 2's ratio of customers using instrument $i$ relative to its customers using other instruments, then these two opposing effects cancel out. Obviously this is not precise, but it suggests that my assumption that merchant 1's residual demand does not shift is a reasonable central case.

\section{$6 \quad$ Further thoughts}

\subsection{Issuer profits and rent dissipation}

For the customer choice criterion, ensuring that customer-merchant pairs choose the best deal for them, it doesn't matter whether a deal is less good because "real" processing costs are high or because of markups; nor, if the latter, whether the quasi-rents are dissipated or not. The key is simply letting two-sided customers pick their best deal.

If one instead (or also) wants to evaluate efficiency, obviously it does matter. Certainly in the US credit card issuers spend lots of resources on marketing (see for example Evans and Schmalensee 2005a, Frankel 2005). Would it be much less with a fee structure (lower interchange than today) that made merchants indifferent?

\subsection{Multi-homing by cardholders: a question}

Many cardholders have more than one card, and many also have access to cash and checks, so there is clearly significant multi-homing in a sense, although Rysman (2006) finds that at least among cards, most consumers put the great bulk of their spending on just one. Rochet and Tirole $(2002,2006)$ argue that pervasive customer-side multi-homing strengthens merchant resistance: a merchant could think, "if I don't take American Express, most Amex cardholders also have Visa or MasterCard, which charge me less." But if Amex offers cardholders higher rebates, a merchant gets a boost in demand from accepting Amex even if all Amex cardholders also have Visa. That is, not every purchase

\footnotetext{
${ }^{23}$ Here I am assuming that merchants 1 and 2 are rivals; I believe one could reverse the signs and make a similar argument if they are complementors.
} 
that a customer would make with his preferred payment instrument will be made if that instrument is not accepted, even if the customer multi-homes.

I conjecture that by the logic of Calculation 1 merchants will rationally accept first not the payment instruments with the lowest $m$, but rather those with the lowest $m+f$. If so, then this would fit with the interpretation of Calculation 1 as saying that it is not a matter of "weakening" merchant resistance, but rather a matter of what merchants resist: total fees $m+f$, not merchant-side fees $m$. But this remains a topic for further analysis.

\subsection{Consumer protection issues}

Non-economists to whom I've mentioned that I was working on issues related to credit cards have mainly assumed that I was studying either the problem of credit card debt or the problem of shrouded contract terms (Mann 2006 reports that solicitations often do not disclose the issuer's terms, which the consumer can learn only by applying for a card). These are surely important issues on which economists should have more to say. Here I note only that if the payment instruments with fee structures tilted strongly toward merchant fees are also the ones that may inveigle unwary consumers into troublesome debt, that reinforces the concerns above. On the other hand, high interchange may keep credit card interest rates down. So far as I know these linkages have not been explored.

\section{$7 \quad$ References}

Baxter, William (1983) "Bank Interchange of Transactional Paper: Legal Perspectives," Journal of Law and Economics, 26: 541-588.

Borenstein, Severin (1996) "Settling for Coupons: Discount Contracts as Compensation and Punishment in Antitrust Lawsuits," Journal of Law and Economics, 39: 379-404.

Chang, Howard, David Evans and Daniel Garcia Swartz (2005) "The Effect of Regulatory Intervention in Two-Sided Markets: An Assessment of Interchange Fee Capping in Australia," Review of Network Economics, 4: 328-358.

Evans, David and Richard Schmalensee (2005a) Paying with Plastic: The Digital Revolution in Buying and Borrowing. MIT Press: Cambridge, Massachusetts.

Evans, David and Richard Schmalensee (2005b) "The Economics of Interchange Fees and their Regulation: An Overview," in Interchange Fees in Credit and Debit Card Networks: What Role for Public Authorities? Federal Reserve Bank of Kansas City. http://www.kansascityfed.org/PUBLICAT/PSR/Proceedings/2005/Evans-Schmalensee.pdf

Farrell, Joseph (2005) "Comments on Chang, Evans and Garcia Swartz," Review of Network Economics, 4: 359-363.

Frankel, Alan (2005) "Interchange fees in Various Countries: Commentary on Weiner and Wright," in Interchange Fees in Credit and Debit Card Networks: What Role for Public Authorities? Federal Reserve Bank of Kansas City. http://www.kansascityfed.org/PUBLICAT/PSR/Proceedings/2005/Frankel.pdf 
Groves, Theodore and John Ledyard (1977) "Optimal Allocation of Public Goods: A Solution to the Free Rider Problem," Econometrica, 45: 783--810.

Guthrie, Graeme and Julian Wright (2006) "Competing Payment Schemes," Journal of Industrial Economics, forthcoming.

Katz, Michael L. (2005) "Commentary: What do we know about interchange fees and what does it mean for public policy?" in Interchange Fees in Credit and Debit Card Networks: What Role for Public Authorities? Federal Reserve Bank of Kansas City. http://www.kansascityfed.org/PUBLICAT/PSR/Proceedings/2005/katz.pdf

Macfarlane, Ian (2005) “Gresham's Law of Payments," http://www.rba.gov.au/Speeches/2005/sp_gov 230305.html

Mann, Ronald (2006) Charging Ahead: The Growth and Regulation of Payment Card Markets Around the World. Forthcoming. Cambridge University Press: Cambridge.

Rochet, Jean-Charles (2003) "The Theory of Interchange Fees: A Synthesis of Recent Contributions," Review of Network Economics, 2: 97-124.

Rochet, Jean-Charles and Jean Tirole (2002) "Cooperation among Competitors: Some Economics of Payment Card Associations," RAND Journal of Economics, 33: 549-570.

Rochet, Jean-Charles and Jean Tirole (2006) "Externalities and Regulation in Card Payment Systems," Review of Network Economics, 5: 1-14.

Rysman, Marc (2006) "An Empirical Analysis of Payment Card Usage," unpublished paper, http://people.bu.edu/mrysman/research/Default.html

Schmalensee, Richard (2002) "Payment Systems and Interchange Fees," Journal of Industrial Economics, 50:103-122.

Schwartz, Marius and Daniel Vincent (2006) "The No Surcharge Rule and Card User Rebates: Vertical Control by a Payment Network," Review of Network Economics, 5: 72102

Weiner, Stuart and Julian Wright (2005) "Interchange Fees in Various Countries: Developments and Determinants," Review of Network Economics, 4: 290-323.

Wright, Julian (2003a) "Optimal Card Payment Systems," European Economic Review, 47: 587-612.

Wright, Julian (2003b) "Pricing in Credit and Debit Card Schemes," Economics Letters, 80: 305-309.

Wright, Julian (2004) "Determinants of Optimal Interchange Fees in Payment Systems," Journal of Industrial Economics, 52: 1-26. 


\section{Appendix: calculations 1 and 2}

Payment instrument $i$ has a cardholder transaction fee of $f_{i}$ and a merchant pertransaction acceptance cost (including merchant fees) of $m_{i}$. Write $c$ for the merchant's other (non-transaction) marginal cost of goods for sale, and $\alpha_{i}$ for the fraction of customers who will use payment instrument $i$ if they buy; for simplicity, following Schwartz and Vincent (2006), I treat this as exogenous, and assume that each group of (potential) customers has the same demand curve $D(\bullet)$, as a function of full price $p+f_{i}$ and in proportion to their numbers $\alpha_{i}$. Then the merchant's total profit is:

$$
\Pi \equiv \sum_{i} \Pi_{i}=\sum_{i} \alpha_{i}\left(p-c-m_{i}\right) D\left(p+f_{i}\right)
$$

The first-order condition for the profit-maximizing nominal price $p^{*}$ is:

$$
\sum_{j} \alpha_{j} \Psi_{j}=0
$$

where $\Psi_{j} \equiv \Pi_{j}{ }^{\prime}\left(p^{*}\right)$ is the slope of the payment-instrument-specific profit function at the optimal nominal retail price $p^{*}$.

We now take this in two directions. First, for Calculation 2, to assess the impact of changes in one instrument's fee structure on the common nominal price $p^{*}$, differentiate the first-order condition (6) totally with respect to $m_{i}$, giving:

$$
0=\alpha_{i} \frac{\partial^{2} \Pi_{i}}{\partial p \partial m_{i}}+\frac{d p}{d m_{i}} \sum_{j} \alpha_{j} \frac{\partial^{2} \Pi_{j}}{\partial p^{2}}
$$

and, similarly differentiating with respect to $f_{i}$,

$$
0=\alpha_{i} \frac{\partial^{2} \Pi_{i}}{\partial p \partial f_{i}}+\frac{d p}{d f_{i}} \sum_{j} \alpha_{j} \frac{\partial^{2} \Pi_{j}}{\partial p^{2}}
$$

Now notice that

$$
\frac{\partial^{2} \Pi_{i}}{\partial m_{i} \partial p}-\frac{\partial^{2} \Pi_{i}}{\partial f_{i} \partial p}=\frac{\partial^{2} \Pi_{i}}{\partial p^{2}}
$$

Hence, subtracting (8) from (7), we have

$$
0=\alpha_{i} \Phi_{i}+\left[\frac{d p}{d m_{i}}-\frac{d p}{d f_{i}}\right] \sum_{j} \alpha_{j} \Phi_{j}
$$

where

$$
\Phi_{i} \equiv \frac{\partial \Pi_{i}}{\partial p^{2}}=-2 D^{\prime}\left(p^{*}+f_{i}\right)-\left(p^{*}-c-m_{i}\right) D^{\prime \prime}\left(p^{*}+f_{i}\right)
$$

If the $\Phi_{j}$ are equal, as they are if demand is linear, then this says that when $m_{i}$ increases by $\mathrm{d} t$ and $f_{i}$ decreases by the same small amount, the nominal price $p^{*}$ increases by 
$\alpha_{i} \mathrm{~d} t / A$, where $A \equiv \sum_{j} \alpha_{j}$. Hence the full price of buying using instrument $i$ (that is, $p^{*}+f_{i}$ ) falls by $\left[A-\alpha_{i}\right] \mathrm{d} t / A$, while that of buying using any other instrument rises by $\mathrm{d} p^{*}=\alpha_{i} \mathrm{~d} t / A$. If demand is not linear then the $\Phi_{j}$ are generally unequal, but they are all equal to the curvature of the profit function evaluated at quite modestly different prices (various adjustments, on the order perhaps of $1-2 \%$, to the same nominal price $p^{*}$ ), so I believe it is a reasonable assumption to treat them as close to equal.

Thus $\alpha_{i}$ customers using instrument $i$ each gain $\left[A-\alpha_{i}\right] \mathrm{d} t / A$, while $\left[A-\alpha_{i}\right]$ customers using other instruments each lose $\mathrm{d} p^{*}=\alpha_{i} \mathrm{~d} t / A$. In other words, with that approximation, the effect is (as in Borenstein 1996) to first order a transfer of surplus from customers using other payment instruments to those using instrument $i$. Assuming that the $D\left(p^{*}+f_{j}\right)$ do not differ much from one another (proportionally), this will remain approximately true. Again, the differences will be small in proportional terms if the differences in $f$ 's are small compared to $p^{*}$, which seems the norm.

Now return to Calculation 1 and consider the impact on $\Pi$ of changes in $m_{i}$ and $f_{i}$. By the envelope theorem we have

$$
\frac{d \Pi}{d m_{i}}=-\alpha_{i} D\left(p^{*}+f_{i}\right)
$$

and

$$
\frac{d \Pi}{d f_{i}}=\alpha_{i}\left(p^{*}-c-m_{i}\right) D^{\prime}\left(p^{*}+f_{i}\right)
$$

Both these last two expressions are negative, and the impact of an increase in $m_{i}$ alone is just the naïve calculation: a one-cent increase in $m_{i}$ costs the merchant one cent times the number of transactions made using payment instrument $i$. But that fails to take internalization into account;

$$
\left[\frac{d \Pi}{d m_{i}}-\frac{d \Pi}{d f_{i}}\right]=-\alpha_{i} \Psi_{i}
$$

I argue that this is small in magnitude compared to the "naïve" estimate $d \Pi / d m_{i}$. This amounts to a claim that $\Psi_{i} / D\left(p^{*}+f_{i}\right)$ is small. The first-order condition on $p$ implies that the weighted sum (over $i$ ) of the $\Psi_{i}$ is zero. To see that each must be small in magnitude relative to $D$, it is enough to conclude that not only do they sum to zero but also they do not differ very much from one another (relative to $D$ ).

We can approximate $\Psi_{i}-\Psi_{j}$ by taking $D^{\prime}$ to be a constant (linear demand), which yields

$$
\Psi_{i}-\Psi_{j} \approx\left[D^{\prime}\right]\left[\left(f_{i}-m_{i}\right)-\left(f_{j}-m_{j}\right)\right]
$$

The ratio of this difference to $D\left(p^{*}+f_{i}\right)$ is equal to the demand elasticity times $\left[\left(f_{i}-m_{i}\right)-\left(f_{j}-m_{j}\right)\right] / p$, which is commensurate with payment-instrument charges as a fraction of retail price, which are normally small in practice. Thus unless the merchant's 
demand elasticity is very high, the terms $\frac{d \Pi}{d m_{i}}-\frac{d \Pi}{d f_{i}}=-\alpha_{i} \Psi_{i}$ not only sum to zero but also do not differ from one another by very much, relative to demand. This argument essentially uses a bound on the size of each $\Psi_{j}$, so although the $\Psi_{j}$ may differ very much from one another proportionally they are all small.

The remaining step is the purely mathematical lemma that: If $x_{1}, \ldots, x_{N}$ are real numbers that sum to zero, and for all $i, j$ we have $\left|x_{i}-x_{j}\right| \leq \varepsilon$, then $\left|x_{i}\right| \leq \frac{N-1}{N} \varepsilon$. To see this, write $x_{i}=\frac{1}{N}\left[N x_{i}-\sum_{j} x_{j}\right]=\frac{1}{N} \sum_{j \neq i}\left[x_{i}-x_{j}\right]$, which is no greater than $\frac{N-1}{N} \varepsilon$ in magnitude. 